De skandinaviska centralbankernas sedelutgifning och guldkassor under kriget Author(s): David Davidson

Source: Ekonomisk Tidskrift, Årg. 17, häft 10 (1915), pp. 317-328

Published by: Wiley on behalf of The Scandinavian Journal of Economics

Stable URL: http://www.jstor.org/stable/3437627

Accessed: 25-06-2016 06:26 UTC

Your use of the JSTOR archive indicates your acceptance of the Terms \& Conditions of Use, available at

http://about.jstor.org/terms

JSTOR is a not-for-profit service that helps scholars, researchers, and students discover, use, and build upon a wide range of content in a trusted digital archive. We use information technology and tools to increase productivity and facilitate new forms of scholarship. For more information about JSTOR, please contact support@jstor.org.

The Scandinavian Journal of Economics, Wiley are collaborating with JSTOR to digitize, preserve and extend access to Ekonomisk Tidskrift 


\title{
De skandinaviska centralbankernas sedelutgifning och guldkassor under kriget.
}

\author{
Af David Davidson.
}

I nedanstående tabell angifves (i millioner kronor) huru dessa centralbankers guldkassor och sedelutgifning gestaltat sig under 1914 och 1915 , och har därvid äfven medtagits dessa bankers avistafordringar på utlandet jämte deras diskontränta.

\begin{tabular}{|c|c|c|c|c|c|c|c|c|c|c|c|c|}
\hline \multirow[t]{2}{*}{ År och dag } & \multicolumn{3}{|c|}{ Sedelutgifning } & \multicolumn{3}{|c|}{ Guldkassa } & \multicolumn{3}{|c|}{$\begin{array}{l}\text { Utländska avista. } \\
\text { fordringar }{ }^{1}\end{array}$} & \multicolumn{3}{|c|}{ Diskonto $^{2}$} \\
\hline & Sv. & D. & $\mathrm{N}$. & Sv. & D. ${ }^{3}$ & N. & Sv. & $\mathrm{D}^{3}$ & $\mathrm{~N}$. & Sv. & D. & N. \\
\hline 191431 jan. & $20 ;$ & I4I & 100 & 103 & 76 & 44 & $3 I$ & 22 & 29 & 5 & 6 & 5 \\
\hline 28 febr. & 214 & I 44 & 102 & IO4 & 78 & 44 & 32 & 22 & 27 & $4^{1 / 2}$ & $5 \quad 4^{1}$ & $1 / 2$ \\
\hline 31 mars & 234 & I 47 & 108 & I04 & 80 & 44 & 27 & 23 & 24 & $»$ & $»$ & $"$ \\
\hline 30 april & 219 & 153 & II I & 104 & 79 & 44 & 24 & 23 & 29 & $\gg$ & $"$ & $"$ \\
\hline $30 \mathrm{maj}$ & 227 & I 57 & II 3 & IOS & 82 & 44 & $3 I$ & 24 & 30 & $"$ & » & $"$ \\
\hline 30 juni & 239 & 160 & I 24 & 105 & 82 & 44 & 24 & 20 & 36 & $4^{1 / 2}$ & 5 & 5 \\
\hline 3 I juli & 228 & 156 & I 24 & IO4 & 78 & 44 & 24 & 14 & 38 & $5^{1 / 2}$ & 6 & 6 \\
\hline 3I aug. & 280 & 194 & 140 & 103 & 75 & 47 & 5 & 25 & 33 & 6 & 6 & $5^{1 / 2}$ \\
\hline 30 sept. & 295 & $2 \mathrm{II}$ & 135 & 103 & 73 & $4 \mathrm{I}$ & $\mathrm{I}, 8$ & 45 & 30 & $"$ & $”$ & 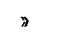 \\
\hline 3 I okt. & 284 & 224 & 133 & 104 & 72 & 40 & 2,6 & $5 I$ & $3 I$ & $»$ & $"$ & $"$ \\
\hline 30 nov. & 284 & 2 II & $13 \mathrm{I}$ & 104 & $8 \mathrm{r}$ & 40 & 6,6 & 47 & 33 & 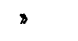 & $"$ & $"$ \\
\hline 3 I dec. & 304 & 207 & 134 & 109 & 95 & 38 & 7,7 & 37 & $3 I$ & » & $"$ & \# \\
\hline 191530 jan. & 267 & 194 & I 24 & 109 & I05 & 38 & 7,5 & 32 & 37 & $5^{1 / 2}$ & $5^{1 / 2}$ & $5^{1 / 2}$ \\
\hline 27 febr. & 277 & 199 & I 29 & I 3 & 105 & 42 & IO & $3 I$ & 40 & » & $"$ & $"$ \\
\hline 31 mars & 292 & $2 I I$ & I39 & I I 3 & 107 & 46 & 30 & $3 I$ & $5 \mathrm{I}$ & $»$ & $"$ & $"$ \\
\hline 30 april & 278 & 209 & 142 & II 3 & 107 & 54 & I3 & 28 & 53 & $"$ & $»$ & $"$ \\
\hline $3 \mathrm{I} \mathrm{maj}$ & 276 & 208 & 135 & II 3 & 107 & 54 & IO & 38 & 62 & $5^{1 / 2}$ & $5^{1 / 2}$ & 5 \\
\hline 30 juni & 293 & 215 & 147 & II 3 & 107 & 54 & 15 & 39 & 68 & $\gg$ & $"$ & $"$ \\
\hline 3 I juli & 276 & 204 & I 44 & II 3 & 107 & 54 & 24 & 33 & $7^{2}$ & $5^{1 / 2}$ & 5 & 5 \\
\hline 3 I aug. & 282 & 203 & I 45 & II 3 & I07 & 54 & 31 & 47 & 77 & $\nu$ & $"$ & $"$ \\
\hline 30 sept. & 310 & 220 & I 49 & $\mathrm{II} 3$ & 107 & - & 38 & 60 & - & 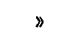 & $»$ & $»$ \\
\hline
\end{tabular}

1 Sveriges riksbank hade dessutom innestående å s. k. separaträkning (d. v. s. å kort tid eller kort tids uppsägning) i utlandet följande belopp under 1914, 28 febr. I,8 mill., 3I mars I,8 mill., 30 april is mill., 30 maj I8 mill., 30 juni 22 mill. och 3 I juli 22 mill. kr.

${ }^{2}$ Vid 19I4 års början var diskontot i Sverige och Norge $5^{1 / 2} \%$. - Sveriges diskonto var 61/2\% 3-27 aug., Norges 61/2\% 3-19 aug. och Danmarks $7 \%$ 4-10 aug.

${ }^{3}$ För jan.-aug. I9I4 ingå i siffran för danska centralbankens guldkassa äfven avistafordringar hos Sveriges, Norges och Tysklands centralbanker.

Ekonomisk Tidskrift. 1915. Häft. Io. 
Den utveckling, hvaraf dessa siffror äro ett uttryck, företer viss öfverensstämmelse för de tre länderna, men denna öfverensstämmelse är ej genomgående, i det att äfven väsentliga skiljaktigheter i utvecklingen förefinnas.

Sedelutgifningen ökas hastigt med krigsutbrottet, i likhet med hvad som skedde i öfriga länder. Mellan 3I juli och 3I augusti I9I4 ökas sedelutgifningen med följande procenttal:

$\begin{array}{ccc}\text { Sverige } & \text { Danmark } & \text { Norge } \\ 22,8 & 24,4 & 13,8\end{array}$

I Norge skulle enligt dessa siffror ökningen varit väsentligt lägre än i de två andra länderna. Men därvid är att beakta, att under månaderna strax före kriget fanns i Norge en tendens till börjande spekulation, som yttrade sig bland annat $i$ en stegring af sedelutgifningen. ${ }^{1}$ Från januari till juni I9I4 var sålunda sedelutgifningens stegring $i$

$\begin{array}{lcc}\text { Sverige } & \text { Danmark } & \text { Norge } \\ 16,6 \% & 13,5 \% & 24 \%\end{array}$

och från januari till augusti I9I4 var totalstegringen i

$\begin{array}{ccc}\text { Sverige } & \text { Danmark } & \text { Norge } \\ 36,6 \% & 37,6 \% & 40 \%\end{array}$

Ökningen af sedelutgifningen i följd af kriget skedde i ett slag redan i början af augusti, såsom framgår af veckorapporterna för Sveriges och Norges centralbanker (Danmarks publicerar som bekant blott månadsrapporter). Sedelutgifningen utgjorde i millioner kronor:

\begin{tabular}{|c|c|c|c|}
\hline \multicolumn{2}{|c|}{ i Sverige } & \multicolumn{2}{|c|}{ i Norge } \\
\hline juli 2 & 206 & juli 22 & I 2 I \\
\hline aug. 1 & 242 & $\Rightarrow \quad 3 \mathrm{I}$ & 123 \\
\hline$\Rightarrow 8$ & 282 & aug. 7 & 152 \\
\hline
\end{tabular}

Till belysning af utvecklingen efter krigets utbrott lämnas följande sammanställning rörande de tre ländernas sedelutgifning (i mill. kronor) i slutet af hvarje månad under åren aug. I9I3-juli I9I4 och aug. I9I4juli 1915

1 Denna föranledde också en stegring af Norges Banks diskonto, som den 24 juni I9I4 höjdes från $4 \frac{1}{2}$ till $5 \%$, under det att Sveriges och Danmarks centralbanker höllo sina diskontosatser oförändrade. 


\begin{tabular}{|c|c|c|c|c|c|c|c|c|c|}
\hline & & & & Dar & ark & & & & \\
\hline & 1913 & 1914 & $\begin{array}{l}\text { ökning i \% } \\
\text { mot föreg. år }\end{array}$ & 1913 & 1914 & $\begin{array}{l}\text { ökning i \% } \\
\text { mot föreg. år }\end{array}$ & 1913 & 1914 & $\begin{array}{l}\text { ling i \% } \\
\text { föreg. år }\end{array}$ \\
\hline aug. & 214 & 280 & 30,8 & I 45 & I94 & 33,8 & 109 & I 40 & 28,4 \\
\hline sept. & 237 & 295 & 24,5 & 146 & $2 I I$ & 44.5 & 109 & 135 & 23,9 \\
\hline okt. & 225 & 284 & 26,2 & 154 & 224 & 45,5 & I09 & I33 & 22,0 \\
\hline nov. & 220 & 284 & 29,0 & I 47 & $2 \mathrm{II}$ & 43,5 & 106 & I3I & 23,6 \\
\hline dec. & 234 & 304 & 30,0 & 152 & 207 & 36,2 & 108 & I34 & 24,0 \\
\hline & I9I 4 & 1915 & & I9I4 & 1915 & & 1914 & I9IS & \\
\hline jan. & 205 & 267 & 30,0 & I4I & I94 & 37,6 & 100 & I 24 & 24,0 \\
\hline febr. & 214 & 277 & 29,4 & I 44 & 199 & 38,2 & 102 & I 29 & 26,5 \\
\hline mars & 234 & 292 & 24,8 & I 47 & $2 I I$ & 43,5 & I08 & 139 & 28,7 \\
\hline april & 219 & 278 & 27,0 & 153 & 209 & 36,6 & I I I & 142 & 27,9 \\
\hline maj & 227 & 276 & 21,6 & 157 & 208 & 32,5 & II 3 & 135 & 19,5 \\
\hline juni & 239 & 293 & 22,6 & 160 & 215 & 34,4 & I 24 & I 47 & I8,5 \\
\hline juli & 228 & 276 & $2 I, 0$ & 156 & 204 & 30,8 & 123 & I 44 & $17, \mathrm{I}$ \\
\hline
\end{tabular}

Af dessa siffror att döma, har sedelutgifningen under aug. I9I4-juli I9I 5 relativt aftagit $\mathrm{i}$ alla tre länderna och det relativa aftagandet har, såvidt ofvan anförda sammanställning kan tillerkännas vitsord (och därom mera strax), varit ungefär lika stort $\mathrm{i}$ alla tre länderna, om man ser på den relativa differensen mellan ökningens maximum och minimum. I Sverige ha vi en sänkning från $30,8 \%$ till $21 \%$, i Danmark från 45,5\% till $30,8 \%$ och i Norge från $28,4 \%$ till $17, \mathbf{1} \%$. Hvad Norge beträffar blir öfverensstämmelsen med de båda andra länderna ännu större, om man tar hänsyn till det nyss påpekade förhållandet, att sedelutgifningen i Norge hade en exceptionell stigning redan i juni I9I4, hvarför de två sista procenttalen (för juni och juli I9I5) icke bli fullt jämförbara med motsvarande procenttal för Sverige och Danmark. Elimineras dessa, blir sänkningen i Norge från 28,4 till $19,5 \%$ och således i det närmaste densamma som i Sverige och Danmark.

Det framgår vidare af nu behandlade siffersammanställning, att stegringen af sedelutgifningen efter krigets utbrott varit betydligt större i Danmark än i Sverige och Norge. I medeltal utgör stegringen (om äfven här för Norge frånses från procenttalen för juni och juli) 26,3 för Sverige, 24,8 för Norge, men 38 för Danmark, d. v. s. den är nära hälften till så stor för Danmark som för de två andra länderna. Det skulle visserligen kunna ifrågasättas, om man kan bygga en dylik slutsats på blott 12 uppgifter pr år om sedelutgifningen; det är ju ej säkert, att dessa uppgifter för den sista dagen i hvarje månad äro tillräckligt tillförlitliga uttryck för sedelutgifningen under hela året. Medelst veckorapporterna borde man ju kunna erhålla säkrare resultat, men sådana publiceras endast för Sveriges och Norges centralbanker, men icke för Danmarks. Emeller- 
tid kunna det oaktadt veckorapporterna för Sveriges och Norges centralbanker användas för att kontrollera riktigheten af det nyss vunna resultatet. Enligt veckorapporterna var sedelutgifningen under tiden aug. 19I4-juli 1915 i Sverige $27,6 \%$ och i Norge 22, r $\%$ högre än under tiden aug. I9I3-juli 19I4. Dessa procenttal öfverensstämma i det närmaste med de medelst månadsrapporterna vunna $26,{ }_{3}$ för Sverige och 24,8 för Norge. ${ }^{1}$ Detta förhållande torde ge ett godt stöd för det berättigade $i$ att lita på det resultat, som här ofvan vunnits på grund af månadsrapporternas siffror angående sedelutgifningen.

Denna sedelutgifningens starka tillväxt efter krigets utbrott har förekommit äfven i andra icke-krigförande länder. Särdeles stark har den varit i Holland och Schweiz, där den uppgått till och stadigt hållit sig vid $50 \%$ eller mer. Omkastningen vid krigets utbrott var följande (siffrorna betyda millioner $£):^{2}$

\begin{tabular}{cr} 
Holland & \multicolumn{2}{c}{ Schweiz } \\
I9I4 25 juli 25,9 & I9I4 23 juli I0,7 \\
I aug. 35,7 & 3 I " I6,4 \\
8 " 38,4 & 7 aug. I7,2
\end{tabular}

Denna stegring har, som sagdt, sedermera bibehållits, såsom framgår af följande tabell angående sedelutgifningen enligt första veckorapporten i hvarje månad under detta och föregående år:

\begin{tabular}{|c|c|c|}
\hline & Holland & Schweiz \\
\hline & I9I4 I9I5 & I9I4 I9IS \\
\hline jan. & $27,8 \quad 4 \mathrm{I}, \mathrm{I}$ & I I,3 I7,3 \\
\hline febr. & $25,4 \quad 37,7$ & 10,7 I6,2 \\
\hline mars & $25,5 \quad 38,2$ & $10,4 \quad I 6$, \\
\hline april & $26,4 \quad 39,2$ & I0,8 I 6,2 \\
\hline maj & $28,7 \quad 4 \mathrm{I}, 2$ & I0,8 I6, \\
\hline juni & $25,7 \quad 40,5$ & 10,6 I6,3 \\
\hline juli & $26,8 \quad 4 \mathrm{I}, 9$ & II $, \mathrm{I} \quad I 6,4$ \\
\hline aug. & $35,7 \quad 42,5$ & 17,2 I 6 \\
\hline sept. & $37, \mathrm{r} \quad 43,3$ & $\mathrm{~J} 7,8$ I 6,2 \\
\hline
\end{tabular}

I Holland har, såsom synes af siffrorna för augusti och september, stegringen fortgått under aug.-sept. 1915, så att sedelutgifningen var be-

1 Beaktar man det ofvan anmärkta förhållandet, att sedelutgifningen i Norge varit i någon mån exceptionell redan några månader före krigets utbrott och därför, hvad Norge beträffar, blott gör jämförelsen mellan tiden aug. I9I3-22 maj 1914 och tiden aug. 1914-22 maj 1915, blir stegringsprocenten för Norge enligt veckorapporterna $23, \mathbf{x} \%$ och kommer sålunda stegringsprocenten enligt månadsrapporterna, 24,8 \%, ännu närmare.

2 Uppgifterna äro tagna ur Economist, hvilket förklarar, att beloppen angifvits i $\mathfrak{E}$. Där har reduktionen från holländskt mynt skett efter relationen I florin $=$ I sh. 8 p.och 25 francs $=$ I $\varepsilon$. 
tydligt större än under motsvarande krigsmånader I9I4. I Schweiz har däremot sedelutgifningen gått något tillbaka $\mathrm{i}$ jämförelse med förra årets första krigsmånader.

I Spanien däremot har ökningen af sedelutgifningnn i följd af kriget varit relativt mycket obetydlig. Enligt Economists ${ }^{1}$ uppgifter var sedelutgifningen 24 juli 191476,8 mill. $£$, I aug. 77,6 och 8 aug. 79,7 mill. $£$. Och vid sistnämnda höjd har den sedermera i det hela bibehållit sig. (Den har under I9I5 icke öfverskridit 8 I mill. £.)

Den ofvan behandlade sammanställningen innebär en jämförelse mellan året före och året efter krigets utbrott. Det är af intresse att fullfölja jämförelsen till de två återstående månaderna augusti och sept., som voro krigsmånader både 19I4 och 1915. Sedelutgifningen var $\mathrm{i}$

\begin{tabular}{|c|c|c|c|c|c|c|c|c|c|}
\hline & \multicolumn{3}{|c|}{ Sverige } & \multicolumn{3}{|c|}{ Danmark } & \multicolumn{3}{|c|}{ Norge } \\
\hline & 1914 & 1915 & ökning i \% & 1914 & 1915 & ökning i \% & I9I4 & I9IS & ökning i \% \\
\hline & 280 & 282 & 0,7 & 194 & 203 & 4,6 & 140 & 145 & 0,4 \\
\hline pt. & 295 & 310 & $5, \mathrm{r}$ & $2 \mathrm{II}$ & 220 & 4,3 & 135 & I 49 & I0 \\
\hline
\end{tabular}

Här föreligger liksom i Holland en ytterligare stegring under I9I 5 gentemot 19I4, ehuru den, utom hvad beträffar Danmark, framträder först i september mănad. Man har emellertid icke rätt.att redan på grund af dessa data antaga, att en väsentlig förändring af sedelutgifningens utveckling i jämförelse med tiden aug. 1914-juli 19I5 inträdt, d. v. s. att det vore att förvänta, att krigsförhållandena skulle framkallat en ny stegring af sedelutgifningen. Åtminstone gäller detta beträffande Sverige. Nedanstående sammanställning af sedelutgifningen enligt månadsrapporterna från och med I9Io till krigets utbrott ger stöd åt detta påstående.

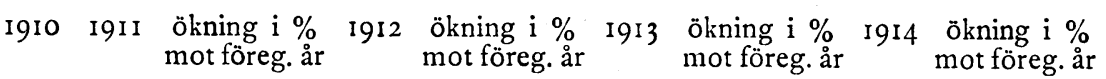

\begin{tabular}{|c|c|c|c|c|c|c|c|}
\hline jan. $\quad 173$ & 176 & 1,7 & 187 & 6,2 & 197 & 5,3 & 205 \\
\hline febr. 176 & 185 & $5, \mathrm{r}$ & I97 & 6,5 & 204 & 3,6 & 214 \\
\hline mars 194 & 206 & 6,2 & 215 & 4,4 & 225 & 4,7 & 234 \\
\hline april I8I & I9I & 5,5 & 199 & 4,2 & 210 & 5,5 & 219 \\
\hline maj I79 & 192 & 7,3 & 199 & 3,6 & 211 & 6,0 & 227 \\
\hline juni $\quad$ I98 & 208 & 5,0 & 214 & 2,9 & 227 & $6, \mathrm{r}$ & 239 \\
\hline juli $\quad$ I80 & 190 & 5,5 & 199 & 4,7 & 206 & 3,5 & \\
\hline aug. I85 & 194 & 4,9 & 208 & 7,2 & $2 \mathrm{I} 4$ & 2,9 & \\
\hline sept. 2 IO & $22 \mathrm{I}$ & 5,2 & 229 & 3,6 & 237 & 3,5 & \\
\hline okt. 201 & 207 & 3,0 & 210 & $\mathrm{I}, 4$ & 225 & $7, \mathbf{x}$ & \\
\hline nov. 190 & 202 & 6,3 & $2 \mathrm{I} 4$ & 5,9 & 220 & 2,8 & \\
\hline dec. 206 & 218 & 5,8 & 228 & 4,6 & 234 & 2,6 & \\
\hline
\end{tabular}

1 Reduktionen från pesetas till $£$ har där skett efter samma norm som för francs $(25 \mathrm{frs}=\mathrm{I} \varepsilon)$. 
Det har sålunda under de senaste åren ej varit ovanligt, att differensen mellan sedelutgifningen för samma månad under två på hvarandra följande år uppgått till det procenttal, hvarmed sedelutgifningen för ultimo sept. I9I5 öfverstigit sedelutgifningen för samma dag I9I4. Det skall visserligen gärna medges, att det kan tvistas om, huruvida den fortgående ganska starka stegring af sedelutgifningen, hvarom tabellen bär vittne, varit för vårt land gagnelig. Denna fråga kan dock ej här behandlas, där det blott gäller att förklara sedelutgifningens stegring sept. I9I 5 öfver siffran för sept. I9I4. Och tabelien visar beträffande denna fråga åtminstone så mycket, att det ej är säkert, att nämnda stegring berott på andra förhållanden än dem, som framkallat de $\mathrm{i}$ tabellen angifna stegringarna under ăren före kriget. - För öfrigt torde böra erinras om, att det belopp, hvarmed sedelutgifningen vid slutet af sept. I9I5 öfverstigit sedelutgifningen vid slutet af aug. I9I5 - eller 27 mill. kronor -, ej är något ovanligt för denna månad. Tabellen utvisar, att motsvarande differenser för åren I9IO-I 3 uppgingo till resp.: 25, 27, 21, 23 mill. kr. och i procent af augusti månads sedelutgifning till resp. $13,5-13,9-10,1-10,7$ procent emot 9,9 procent för ăr 1915 .

Det sagda afser emellertid icke, att frågan med detta vore utredd, utan blott att den ännu icke kan afgöras. Och naturligtvis är det all anledning för riksbankens styrelse att ha sin uppmärksamhet fäst på förhållandet.

Tabellen å sid. 3I7 visar, att äfven guldkassornas forändringar varit ganska olika $\mathrm{i}$ de tre länderna.

I Sverige var - om man frånser från den minskning, som ägde rum strax vid krigets utbrott och hvilken som bekant berodde på uttag för inhemsk räkning $\mathrm{i}$ och för skrinläggning ${ }^{1}$ och hejdades, genom att riksbanken upphörde med inlösningen af sina sedlar - guldkassan oförändrad till dec. I9I4, då den steg med 5 mill. under nämnda månad och med 4 mill. under februari. Inalles sålunda en stegring med 9 mill. kr. eller $8,7 \%$.

I Danmark, där äfven uttag skedde vid krigets utbrott, har guldkassan sedermera undergått en högst betydande stegring, nämligen från 72 mill. kr. den 3 I okt. I9I4 till IO7 mill. den 3 I mars i år, eller med i det allra närmaste $50 \%$.

${ }^{1}$ Under dagarna 29 juli-I aug. uttogos på detta sätt 2,7 mill. kr. 
I Norge utsattes också centralbankens guldkassa för en åderlåtning - och detta en ganska stark sådan. Huru stor denna var vid krigets utbrott, kan ej utläsas af veckorapporterna, enär posten "guldbeholdning» i dessa omfattar äfven avistafordringar på utlandet. Månadsrapporterna åter utvisa, att mellan den $3 \mathrm{I}$ juli och $3 \mathrm{I}$ aug. I9I4 guldkassan steg med 3 mill. (från 44 till 47 mill. kr.). Men därefter sjunker den, så att den den 3 I okt. är 40 mill. och 30 jan. 38 mill. kr. Därefter stiger den däremot betydligt och hastigt, så att den redan 30 april I9I 5 uppgår till 54 mill. kronor, hvilket belopp sedan förblir oförändradt. Stigningen från 30 jan. till 30 april utgör sålunda $42 \%$; äfven i jämförelse med kassans storlek före kriget (vid juli månads utgång), då den utgjorde 44 mill., är stegringen ändock $22,7 \%$.

Ökningen af Danmarks och Norges guldkassor öfversteg således högst betydligt ökningen af Sveriges.

Sveriges guldkassa ökades under tiden dec. 1914-febr. 1915; Danmarks under tiden nov. 19I4-mars I9I 5 och Norges under tiden febr.-april 19I5. Under den tidsperiod, under hvilken ökningen i Norge skedde, försiggick en ganska betydande guldexport från Sverige. Enligt engelska handelsstatistiken emottog nämligen England från Sverige under februari $25,000 £$, under mars $425,000 £$ och under april I00,000 $£$ d. v. s. sammanlagdt (efter parikursen I8,16 kr. pr $£$ ) i det närmaste Io mill. kronor.

De guldförvärf, som de skandinaviska länderna sålunda gjort under kriget, äro dock betydligt mindre än vissa andra neutrala stater kommit i åtnjutande af. De nyss beträffande sedelutgifningen omnämnda staternas guldkassor (Hollands, Schweiz' och Spaniens) uppgingo nämligen till följande belopp (i mill. $£$ och enligt Economist):

\begin{tabular}{|c|c|c|c|c|c|c|}
\hline \multicolumn{2}{|c|}{ Holland } & \multicolumn{2}{|c|}{ Schweiz } & \multicolumn{3}{|c|}{ Spanien } \\
\hline I9I4 juli & 13,5 & I9I4 juli 2 & 7,2 & I9I 4 juli & 25 & $2 \mathrm{I}, 7$ \\
\hline I9I5 sept. & 32 & I9I 4 sept. 3 & 9 & I9Is april & 17 & $24, \mathrm{r}$ \\
\hline & & 1915 sept. 3 & 9,7 & I915 sept. & 25 & 30 \\
\hline
\end{tabular}

För Holland är det sålunda en stegring af $137 \%$ och ökningens absoluta belopp i svenskt mynt uppgår till omkring 335 mill. kronor. För Spanien stannade ökningen vid nära $40 \%$ med ett absolut belopp af I 50 mill. kronor. Blygsammast var ökningen för Schweiz: nära $35 \%$ och med ett belopp af 45 mill. kronor.

En redogörelse för guldkassornas förändringar bör ju kompletteras med uppgifter om avista-fordringar eller inom kort tid förfallna fordringar 
på utlandet efter afdrag af motsvarande skulder. I tabellen sid. 317 har därför upptagits de skandinaviska centralbankernas utländska avista-fordringar. Emellertid borde äfven de enskilda bankernas fordringar af samma slag upptagits, men härom finnas publicerade uppgifter blott för Sverige. Jag kan därför icke ingå på några kommentarier af dessa siffror.

Centralbankernas diskontosatser förete ju ej obetydliga såväl absoluta som relativa omkastningar. Båda dessa ha ju varit föremål för olika bedömanden. Beträffande diskontosatsernas absoluta storlek har frågan gällt, dels om denna varit tillräcklig, dels om höjning ej skett för sent eller sänkning för tidigt. Denna punkt lämnar jag här åsido. Med hänsyn till förhållandet mellan de olika ländernas diskontosatser lämnar tabellen å sid. 3I 7 äfven intresseväckande upplysningar. Ända till fram i juni 1914 var diskontot i Danmark högre än i Sverige och Norge, som hade samma diskonto. I juni 1914 höjer Norge sitt till likhet med Danmarks. En vecka i augusti (4-IO) var diskontot i Danmark högre än i Sverige och Norge, som åter hade lika diskonto, men under tiden II-I9 augusti var diskontot i Sverige och Norge högre än i Danmark, och mellan 19-27 augusti var diskontot $6 \frac{1}{2} \%$ i Sverige, $6 \%$ i Danmark och $5 \%$ i Norge. Vid slutet af augusti hade Sverige och Danmark lika diskonto $(6 \%)$ och högre än Norges $(5 \%$ \% $1 / 2$ och så förblef det till början af jan. I9I 5 , då allạ de tre länderna fingo lika diskonto $(5 \%$ \% $1 / 2$. Därefter sänkte Norge sitt diskonto i maj och Danmark sitt $\mathrm{i}$ juli, under det att Sverige behöll och fortfarande behållit sitt diskonto oförändradt. För närvarande har sålunda Sverige högre diskonto än Danmark och Norge.

Antalet tänkbara kombinationer med hänsyn till relationerna mellan de tre ländernas diskonton är I3. Af detta antal voro 7 representerade under en tid af $\mathrm{I} 1 / 2$ år och detta så, att två af dessa kombinationer återkommo hvar och en två särskilda gånger. ${ }^{1}$

Svenska riksbankens åtgärd att icke längre inväxla danska sedlar till deras nominella värde utan för I00 kronor i danska sedlar blott lämna

1 Det är här icke fråga om diskontosatsernas absoluta storlek resp. ändringar däri, annat än så vidt denna storlek har inflytande på relationen mellan diskontosatserna $\mathrm{i}$ de tre länderna. Sv. $6 \%$, D. $5 \%$ och N. $5 \%$ samt Sv. $5 \%$, D. $4 \%$ och N. $4 \%$ betraktas sålunda såsom samma relation; vidare har den grad, hvari det ena landets diskontosats varit större eller mindre än det andras, här ej tillmätts någon betydelse. 
99 kr. 25 öre i svenska sedlar, hvilken åtgärd vunnit efterföljd i Norge, har framkallat en gensaga af den danske professorn i nationalekonomi Axel Nielsen. Enligt referat i svenska tidningar af prof. Nielsens uttalande skulle hans mening vara, att ătgärden stode $\mathrm{i}$ strid med skandinaviska myntunionens andemening och för öfrigt ledde till den konsekvensen, att svenska (och väl äfven norska) sedlar skulle i Danmark drabbas af samma värdesänkning.

Detta uttalande kräfver några kommentarier, isynnerhet som det står $\mathrm{i}$ ett visst samband med det ämne, som behandlas i denna artikel.

De omständigheter, som ledt till den svenska riksbankens åtgärd, ha ej uppstått forst nu, utan äro af äldre datum. Af riksbankens årsböcker framgår, att utväxlingen af sedlar mellan Sveriges riksbank och danska Nationalbanken sedan 1904 tedde sig på följande sätt:

$\mathrm{J} 904$

1905

1906

1907

1908

1909

1910

I9I I

I9I 2

1913

I9I 4

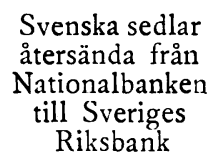 \\ Svenska sedlar \\ Nationalbanken \\ Riksbank}

$$
\begin{array}{r}
15,8 \\
17,4 \\
18,6 \\
20,5 \\
19,2 \\
19,3 \\
19,7 \\
16,8 \\
3,6 \\
1,4 \\
1,6
\end{array}
$$

\author{
Danska sedlar \\ återsända från \\ Sveriges Riks- \\ bank till \\ Nationalbanken
}

Under det att sålunda till och med I9IO det vid detta utbyte af sedlar uppstod ett öfverskott af svenska sedlar, som varierade mellan 2,8 mill. och 6,2 mill., omkastades förhållandet därefter, så att under åren. I9I I-I9I4 danska sedlar visade ett öfverskott, som uppgick I9I I till 3,3 mill., I9I2 till 22,2, I9I3 till 26,9 mill. och I9I4 till 34,x mill. kronor. Och för den gångna delen innevarande år har öfverskottet varit proportionsvis ännu större. ${ }^{1}$

1 Äfven utväxlingen af sedlar mellan Sverige och Norge har att uppvisa en liknande, ehuru ej på långt när lika utpräglad utvecklingstendens, såsom nedanstăende sammanställning visar: 
Hela utväxlingen af sedlar mellan de båda länderna framgår ej af dessa siffror. En stor del suenska sedlar ha efter I9I I från Danmark återgått till Sverige genom privat förmedling. Detta har berott på, att Danmark har ett öfverskott af förfallna skulder till Sverige, och att detta förhållande föranledt danska Nationalbanken att så till vida afvika från principerna i den år I886 mellan de tre skandinaviska centralbankerna ingångna öfverenskommelsen angående inbördes afräkning beträffande förfallna skulder och fordringar, att Nationalbanken tagit en liten provision af, efter hvad det säges, I à I $1 / 2$ promille vid anvisningar på Sveriges Riksbank. ${ }^{1}$ Detta hade till följd, att de i Danmark cirkulerande svenska sedlarna uppsamlades på enskild väg och användes till betalning af danska skulder till Sverige. Detta förklarar till en del den ofvan angifna differensen mellan återsända svenska och danska sedlar; till en del berodde väl differensen på, att danska sedlar i större utsträckning användes till betalningar till svenskar än svenska sedlar till betalningar till danskar. Då den på privat väg skeende återsändningen af svenska sedlar från Danmark till Sverige väl medför, att sedlarna hastigare återgå till sitt hemland, än då återsändningen förmedlas genom centralbankerna, äger man sålunda rätt att antaga, att

I) tillflödet af danska sedlar till Sverige är större än af svenska sedlar till Danmark och

2) de svenska sedlarna stanna kortare tid i Danmark än de danska sedlarna i Sverige.

\begin{tabular}{|c|c|c|}
\hline & $\begin{array}{c}\text { Svenska sedlar } \\
\text { återsända från } \\
\text { Norges Bank } \\
\text { till Sveriges } \\
\text { Riksbank }\end{array}$ & $\begin{array}{c}\text { Norska sedlar } \\
\text { återsända från } \\
\text { Sveriges Riks- } \\
\text { bank till Nor- } \\
\text { ges Bank }\end{array}$ \\
\hline 1904 & 10,4 & 10,3 \\
\hline 1905 & 8,7 & 10,7 \\
\hline 1906 & 8,5 & 9,7 \\
\hline 1907 & $9, \mathrm{I}$ & 10,3 \\
\hline 1908 & $8, o$ & 10,5 \\
\hline 1909 & 7,3 & IO, 6 \\
\hline 1910 & 8,3 & $\mathrm{I}_{3}, \mathrm{O}$ \\
\hline I9I I & 8.0 & I 4,6 \\
\hline 1912 & 8.6 & 15,5 \\
\hline 1913 & 8,7 & 20,0 \\
\hline 1914 & 8,8 & I9,6 \\
\hline
\end{tabular}


Detta betyder, att det i allmänhet finnes ett större antal danska sedlar i Sverige än svenska sedlar i Danmark. Och vidare äger man rätt att antaga, att denna differens är i tillväxt. ${ }^{1}$

Det kan nu ej anses vara förenligt med principerna för svensk lagstiftning på föreliggande område, att en allt större och större mängd danska sedlar komma att cirkulera i Sverige. Svensk lag förbjuder andra svenska banker än riksbanken att utgifva sedlar, och med denna princip är det ej förenligt, att ett främmande lands sedlars cirkulation i Sverige skulle på något sätt auktoriseras, och detta allra minst, när det, som nu, är fråga om oinlösliga sedlar. Att lagstiftningen ej gått ännu längre och förbjudit cirkulation af främmande lands sedlar, beror naturligtvis bl. a. därpå, att ett dylikt förbud dels hittills icke varit behöfligt, dels icke skulle kunna göras effektivt.

Icke heller kan mạn ur den skandinaviska myntkonventionen utläsa något annat. Det är visserligen så, att enligt denna konvention äfven hvarje lands skiljemynt är (inom viss gräns) lagligt betalningsmedel i de öfriga länderna. Men därvid har, jämte det en tyst förutsättning varit, att sådant mynt endast komme att utgifvas i begränsad mängd, bl. a. uppställts den garatien, att hvarje land är skyldigt att på anfordran inväxla sitt skiljemynt mot guldmynt. Att häri se något slags indirekt erkännande af gångbarheten äfven af sedlar, som utges i stora mängder och utan garantien af inväxlingsskyldighet, är ju icke alls rimligt. ${ }^{2}$

Det står naturligtvis äfven Nationalbanken fritt att, såsom prof. Nielsen uttalar, fordra afgift för inlösen af svenska sedlar. Men då redan nu endast obetydliga belopp dylika sedlar inkomma till banken, lär den icke få tillfälle att uppbära dylik afgift.

Härmed har jag icke velat uttala något om den sannolika verkan af den svenska riksbankens åtgärd. Kanske äfven denna kommer att bli utan verkan. Då uppstår visserligen faran för, att danska sedlar ändock kunde komma att cirkulera i Sverige. Precedensfall förefinnas. ${ }^{3}$

${ }^{1}$ Huru stor mängd danska sedlar äro utelöpande i Sverige, är ju svårt, om ens möjligt att utröna. Antagligen befinner sig största delen af dessa sedlar i Skåne, enär det väl är där, som de hufvudsakligaste danska uppköpen ske. Dessutom ha de danska sedlarna lättare att hålla sig kvar i rörelsen där än annorstädes i Sverige.

${ }^{2}$ Se Bet. af den för de tre nordiska konungarikena anordnade myntkommission I 873 , sid. 16 .

3 Som bekant blef följden af, att engelska staten ej inlöste guldmynt med så stor nötning, att de ej längre voro lagligt betalningsmedel, den, att dessa nötta mynt $i$ allmänhet ej kommo in till statskassorna, utan stannade i allmänna rörelsen, som därigenom allt mer och mer fylldes af underhaltiga guldmynt. Därigenom framtvangs ommyntning på statens bekostnad. 
En af Nationalbankens direktörer lär ha, under erkännande af det berättigade $\mathrm{i}$ svenska riksbankens åtgärd, yttrat, att danskarna för framtiden få upphöra att använda danska sedlar såsom betalningmedel $\mathrm{i}$ Sverige och i stället söka skaffa sig svenska betalningsmedel. Mot detta uttalande är ju intet annat att anmärka, än att det icke berör en icke riktig anledning till danska köpares ifrågavarande förfarande, nämligen att diskontot är $1 / 2$ procent lägre i Danmark än i Sverige, och att detta gör, att svenska pengar bli dyrare att anskaffa än danska. Riksbankens åtgärd leder till att $\mathrm{i}$ ungefär motsvarande grad fördyra användningen af danska pengar (sedlar) i Sverige. Den synpunkten tyckes professor Nielsen icke ha tänkt på och öfverhufvud icke på, att försöket att genom analogier eller andemeningar utvidga den skandinaviska myntkonventionens tillämplighetsområde stöter på ett oöfverstigligt hinder i de särskilda ländernas fria herravälde öfver sitt diskonto, ett herravälde, som väl icke heller prof. Nielsen önskar se inskränkt.

Det skulle härefter återstå att behandla frågan om orsakerna till och verkningarna af den starka sedelutgifningen sedan krigets början. Till denna del af ämnet skall jag återkomma i en följande uppsats. 